\title{
Development and Psychometric Testing of the Supportive Care Needs Scale for Patients with Tuberculosis (SCN-TB)
}

\author{
Jing Ren (D) \\ Dongfang $\mathrm{Han}^{2}$ \\ Jingjun Zhang' \\ Yingli Wang $\mathbb{D}^{3}$ \\ Qiaoqiao Huang ${ }^{4}$ \\ Tian Tian (D) \\ Xiaomei Li (iD)
}

'School of Nursing, Health Science Center, Xi'an Jiaotong University, Xi'an

City, People's Republic of China;

${ }^{2}$ Department of Obstetrics and Gynecology, First Affiliated Hospital of Xi'an Jiaotong University, Xi'an City, People's Republic of China; ${ }^{3}$ Department of Internal Medicine of Tuberculosis, Fourth Hospital of Inner Mongolia Autonomous Region, Hohhot City, People's Republic of China; ${ }^{4}$ Department of Nursing, Fourth Hospital of Inner Mongolia Autonomous Region, Huhhot City, People's Republic of China
Correspondence: Xiaomei Li School of Nursing, Health Science Center Xi'an Jiaotong University, No. 76 Yanta West Road, Yanta District, Xi'an City, Shanxi, 71006I, People's Republic of China

$\mathrm{Tel} / \mathrm{Fax}+862982657017$

Email roselee8825@I26.com
Purpose: Patients affected by tuberculosis have diverse unmet supportive care needs (SCN) that may seriously affect their treatment adherence. Accurately assessing patients' SCN is important for providing efficient patient-centred care, but few instruments are suitable for use in clinical practice. Therefore, the purpose of this study was to develop an SCN scale for patients with tuberculosis (SCN-TB) and to evaluate its psychometrical properties.

Patients and Methods: Based on the SCN framework, the SCN-TB was designed via a literature review, Delphi consultation and pilot study. Then, 550 patients from four tuberculosis specialist hospitals in Shaanxi Province were enrolled by convenience sampling to further test the validity and reliability of the SCN-TB.

Results: A total of 518 patients completed the survey. The final scale encompasses 25 items in five domains: physical, practical, psycho-emotional, social, and informational. The content validity for the scale was 0.93 , with that for each item ranging from 0.80 to 1.00 . Five factors that explained $80.38 \%$ of the variance were identified in exploratory factor analysis. A five-factor model was then confirmed with confirmatory factor analysis using maximum likelihood estimation with bootstrapping. The model fit indices were $\chi^{2} / d f=1.062$ (Bollen-Stine $\chi^{2}=281.382$, $d f=265, p<0.001), \mathrm{CFI}=0.997, \mathrm{RMSEA}=0.016, \mathrm{SRMR}=0.053, \mathrm{NFI}=0.951$, and $\mathrm{GFI}=0.929$. All factors had acceptable convergent and discriminant validity. The Cronbach's $\alpha$, split-half, and test-retest reliability coefficients of the scale were $0.884,0.883$, and 0.854 , respectively.

Conclusion: The SCN-TB is a valid and reliable theory based tool for assessing the needs of patients with tuberculosis and can be applied in both clinical practice and research.

Keywords: needs assessment, tuberculosis, patient-centered care, quality of healthcare, supportive care

\section{Introduction}

Tuberculosis (TB) remains a major global health concern. There were an estimated 10.0 million new cases of TB worldwide in 2019, and China ranked third among 30 countries with a high TB burden. ${ }^{1}$ Patients with confirmed TB have to take a combination of drugs during short-course chemotherapy lasting at least 6 months. ${ }^{2}$ Meanwhile, they are also asked to make numerous behavioural in dietary and lifestyle changes, and undergo multiple hospital admissions to be examined., Thus, consistent adherence to treatment is key for TB patients to achieve good therapeutic outcomes. However, the complex treatment process may result in patients with myriad unmet supportive care needs $(\mathrm{SCN})$, which in turn impair their compliance and lead to poor health outcomes. ${ }^{5}$ 
SCN are broadly defined as requirements for care that enables management of symptoms and side effects, adaptation and coping, facilitates understanding and informs decision making during treatment. ${ }^{6-8}$ Patients affected by TB frequently suffer serious symptoms and side effects and experience undesirable effects that impact their life, such as a reduced capacity to perform daily activities. ${ }^{9}$ Moreover, poor knowledge of disease symptoms and treatment often exposes patients to non-adherence problems, such as irregular medication use and interruptions in regimens. ${ }^{10,11}$ In particular, there is a high prevalence of psychological distress among TB patients due to, for example stigma and depression, which adversely affect their cognitive functioning and ability to cope with stress at home and work. ${ }^{12,13}$ In recent years, although efforts have been made to promote TB care, many patients are still not accessing appropriate health services timely to address their needs. ${ }^{14}$ TB patients who experience unmet SCN are more likely to suffer prolonged infection, relapse and even drug resistance. ${ }^{5,10,11}$ Additionally, increased evidence has demonstrated that unmet SCN can also lead to a heavy financial burden for TB patients and a waste of medical resources. ${ }^{15,16}$ Therefore, the TB patient-centred care model proposed by the World Health Organization (WHO) clearly states that it is essential for healthcare providers to identify TB patients' $\mathrm{SCN}$ before tailoring and delivering interventions. ${ }^{17}$

Identifying patient needs is premised on an effective and reasonable instrument. Many recent studies have explored the care needs of TB patients from a qualitative perspective. ${ }^{11,14}$ There is only one instrument, PNI-TB, ${ }^{18}$ that has been used in several studies to assess TB patient needs quantitatively. Even so, this instrument only focused on psychosocial needs, ignoring other important needs of TB patients. Researchers have also used quality of life tools, such as the QLICD-PT ${ }^{19}$ and SGRQ, ${ }^{20}$ as references to explore TB patient needs. Quality of life measures provide insights into the symptoms experienced by patients; however, they do not explicitly reveal what patients want from healthcare professionals and fail to link their experience directly with care needs. ${ }^{21,22}$ The measurement of SCN for TB patients could provide evidence-based guidance to inform clinical practice. Accordingly, the lack of a need scale weakens support interventions for TB patients with high levels of unmet $\mathrm{SCN}$. For these reasons, developing a valid and reliable scale to comprehensively assess the SCN of TB patients is essential.
In 2000, the Supportive Care Needs Framework (SCNF) was developed to help health professionals ensure that the needs of cancer patients are met within all domains of care. ${ }^{23}$ This framework comprises physical, informational, psychological, spiritual, practical, emotional and social domains. ${ }^{24}$ The SCNF has been widely referred to in studies investigating the unmet SCN of patients with, for example, $\mathrm{HIV}^{25}$ stroke $^{26}$ and diabetes. ${ }^{27}$ Therefore, it can serve as a useful and comprehensive framework for understanding the needs of TB patients. To address the lack of a comprehensive needs assessment instrument for TB patients, this study aimed to develop an SCN scale for patients with TB (SCN-TB) under the guidance of the SCNF, and to verify its psychometric properties.

\section{Materials and Methods}

An instrument development process was applied that comprised two phases: (1) item generation and (2) psychometric testing.

\section{Phase I: Item Generation}

The item pool of the SCN-TB was generated based on a literature review, Delphi consultation, and pilot study. A literature review was performed by searching English databases (PubMed, Web of Science, Embase, Google Scholar, and CINAHL) and Chinese databases (CNKI, Wan Fang and VIP) with the keywords "tuberculosis", “ pulmonary tuberculosis", "supportive care", "healthcare", "practical", "spiritual”, "social”, "psychological”, "informational", "emotional", "physical", "support" and "need". Articles were selected if they reported data documenting one or more SCN of TB patients. Referencing the SCNF, data from the included articles were organized into a table to facilitate comparison and thematic analysis. Finally, a pool of 49 items was developed, and the items were categorized into seven domains. Each item asked TB patients to consider their level of need for help by choosing one of the following response options: $1=$ no need-not applicable, $2=$ no need-already satisfied, $3=$ low need, $4=$ moderate need, or 5=high need. ${ }^{28}$ No items needed to be reversed scored, and higher scores reflected a higher level of need.

Subsequently, a two-round Delphi survey was conducted to screen the items included in the SCN-TB item pool. ${ }^{29}$ A total of 15 experts were recruited by email invitation, including two TB prevention and control researchers, two clinical diagnosis and treatment 
physicians, three nurse leaders, two senior clinical nurses, three TB educators, and three nursing professors with expertise in theory construction and instrument development. In round one, the survey was presented with a brief introduction to the aim of the study, theoretical underpinnings, and development process. Experts were invited to provide personal information (eg, age, education level, and work experience), make suggestions regarding additional needs content using a free-text format, and rate each of the proposed items. All items were assessed on a scale from 1 (less important) to 5 (most important). The research team discussed the items with suggested adaptation of the language and those with less importance. The items were changed or deleted as necessary. In the second round, the experts were presented with the changes made based on feedback from the first round and invited to re-assess the items' relevance and provide additional rewording suggestions, comments, and questions. Through this process, items were deleted, rewritten, and added as necessary, and then assessed for content validity.

The content validity index (CVI) calculated in the final round of the Delphi survey was used to evaluate the content validity of the scale. The CVI for an item is the proportion of experts who rated it as 4 or 5 . The CVI was calculated for each item (I-CVI) and scale (S-CVI). The $\mathrm{S}-\mathrm{CVI}$ was required to be greater than 0.8 , suggesting that the content validity of the scale was good. ${ }^{30}$

Once the draft scale was created, a pilot study was conducted to evaluate its clarity, understandability, and feasibility. Thirty patients were recruited from a specialized TB hospital using convenience sampling. Eligible patients were aged $\geq 18$ years, had a diagnosis of $\mathrm{TB}$, were conscious and were able to answer questions. We excluded patients with cognitive impairment, mental illness, and any other severe physical problems or serious organ injuries. Written informed consent was obtained from all participants.

\section{Phase 2: Psychometric Testing} Sample and Setting

A cross-sectional study was conducted to test the psychometric properties of the SCN-TB. The sample size was determined based on the number of items in the draft scale and the requirements of factor analysis. It has been suggested that 5 10 participants per item is the minimum sample size. ${ }^{31}$ In the current study, the initial number of items was 25 , and with an estimated sample attrition of 30\%, 163-325 participants were required. Confirmatory factor analysis (CFA) samples should be include at least 200 participants, ${ }^{32}$ so a total of $363-525$ participants were required for the study. The inclusion and exclusion criteria were consistent with those of the pilot study. A convenience sample of 550 participants was recruited at four specialized TB hospitals in Xi'an, Shaanxi Province. To assess the test-retest reliability, 50 patients agreed to complete the questionnaire twice within a suggested interval of two weeks. $^{33}$

\section{Data Collection}

Potential participants were met at inpatient clinics by two trained investigators. They were given a cover letter informing them about the purpose of the study, it's voluntary nature, and anonymity concerning participation. Those who agreed to participate were asked to sign an informed consent form and to fill out the questionnaires independently. The questionnaires were composed of two parts: demographic questions and the draft SCN-TB. Patients who participated in the test-retest study were sent an electronic version of the questionnaire via WeChat (a Chinese social media platform) two weeks later.

\section{Data Analysis}

All statistical analyses were performed using IBM SPSS 26.0 (IBM Corp., Armonk, NY) expect for CFA, which was performed with AMOS 24.0 (AMOS Development Corp., USA) software. Continuous variables are presented as the mean and standard deviation (SD). Categorical variables are presented as numbers and frequencies. The psychometric properties of the SCN-TB were tested for validity and reliability. Generally, the $\alpha$ level was 0.05 .

\section{Item Analysis}

Item analysis aims to determine whether each item is correlated with the total score. An item was eliminated if it met one or more of the following criteria: (i) the critical ratio value of an item was found to be nonsignificant; (ii) the mean of the item was extreme, or its variance was zero; or (iii) the item-total correlation coefficient was not significant, or the coefficient was $<0.30 .{ }^{34}$

\section{Validity Analysis \\ Construct Validity}

Exploratory factor analysis (EFA) and CFA were performed to examine the construct validity of the scale. ${ }^{35}$ The sample was split into two subsamples, using the random-assignment function in SPSS. The equivalence of demographic characteristics between the two subsamples was examined through chi-square tests (for categorical data) and Mann-Whitney $U$-tests (for continuous variables). 


\section{Exploratory Factor Analysis}

EFA was conducted to identify the initial factor structure of items with subsample 1. Bartlett's test of sphericity and the Kaiser-Meyer-Olkin (KMO) test were used to check the factorability of the data. EFA using principalcomponents analysis with varimax rotation was performed to explore the factor structure of the draft SCN-TB. The number of factors was determined by the eigenvalues and the scree plot. Factors with eigenvalues $>1$ were extracted, and the result was considered good when at least $60 \%$ of the variance was explained by the identified factors. According to the scree plot, the number of factors is indicated by the point at which the line indicating the slope begins to flatten. ${ }^{36}$ We also assessed the EFA solution based on multiple criteria: primary factor loadings $>0.40$, cross-loadings, the threshold for item communality $\left(h^{2}\right)$ being $>0.40$, the interpretability of the factor structure and the theoretical sense of the factors. ${ }^{37}$

\section{Confirmatory Factor Analysis}

The fit of the model, which was extracted by EFA, was validated with subsample 2 using CFA. Mardis's normalized estimate of multivariate kurtosis $(<5)$ was used to test the multivariate normality of the data; however, preliminary analysis revealed that the data violated the multivariate normality assumption (Mardia's coefficient=18.201) ${ }^{33}$ Therefore, the Bollen-Stine bootstrapped (5000 bootstrap samples) maximum likelihood estimation was used for the model. ${ }^{38}$ The model fit indices included the Bollen-Stine chi-square value/degree of freedom $\left(\chi^{2} / \mathrm{df},<3\right)$, the root mean square error of approximation (RMSEA, <0.08), the comparative fit index (CFI, >0.90), the goodness-of-fit index (GFI, $>0.90$ ), the standardized root mean square residual (SRMR, <0.08), and the normed fit Index (NFI, >0.90). ${ }^{39}$

Additionally, the average variance extracted (AVE), construct reliability (CR) and the correlation coefficients between factors were calculated to validate the discriminant validity and convergent validity of the subfactors. An AVE $>0.50$ and $\mathrm{CR}>0.70$ indicated good convergent validity, and a square root of AVE greater than the correlation coefficient between factors indicated good discriminant validity. ${ }^{40}$ The discriminant validity of the total SCN-TB score to compare selected participant subgroups was also tested using the Mann-Whitney test (for two subgroups) or Kruskal-Wallis test (for three or more subgroups).

\section{Reliability Analysis}

Internal consistency was tested using Cronbach's alpha coefficient for the overall scale and each domain. Split-half reliability was determined by dividing all of the items into odd-even parts according to the number and computing the correlations of the scores between the two parts. The Pearson correlation coefficient was calculated between the scores of the 50 patients who completed the SCN-TB twice at a two-week interval to determine the test-retest reliability. A statistically acceptable reliability coefficient for the total scale and a domain is $>0.7$ and $>0.6$, respectively. ${ }^{41}$

\section{Results}

\section{Phase I: Item Generation}

During the item selection stage, a two-round Delphi survey was conducted to elicit expert opinions regarding the specific items included in the SCN-TB. The response rate for the Delphi survey was $100 \%$ for both rounds. The 15 experts all held a bachelor's degree or a higher qualification, and their average work experience in their respective professional fields was $27.93(\mathrm{SD}=8.91)$ years.

In the first round, 30 items received an aggreement of over $80 \%$ from the experts regarding wording and relevance, and 19 items were removed. After considering the experts' suggestions, nearly all items were revised for wording and 2 items were added. As this study was conducted in the context of China, 93.3\% of the experts (14/ 15) suggested that the original SCNF should be modified to five domains: practical, social, informational, physical, and psycho-emotional. Following the second round, 4 items were dropped and 3 items were merged becasue of overlapping content with other items. Finally, 25 items were selected to include in the SCN-TB: five items per domain. The revised draft scale after the two-round Delphi survey is showed in Supplementary File 1.

In the final round of the Delphi survey, the CVI ranged between 0.80 and 1.00 for each item, and the S-CVI was 0.93 , which indicated that most experts regarded the items as relevant or very relevant to TB patients' SCN; the SCN-TB was found to be acceptable for further use. In the pilot study, all participants understood each item well and took 8-10 min to complete the scale. Major adjustments were unnecessary.

\section{Phase 2: Psychometric Testing} Sample Characteristics

A total of 550 participants completed the SCN-TB, and $518(94.18 \%)$ questionnaires were valid. A total of 53.9\% 
of participants were male, and the average age was 32.06 $(\mathrm{SD}=6.89)$ years. Other characteristics of the subjects are shown in Table 1. No differences were found between the two subsamples concerning all of the characteristics.

\section{Item Analysis}

The means of all items ranged from 3.09 to 3.86, and there were no items with a variance of zero. The critical ratio was significant for all items, and the item-total correlation was $>0.30$. There were no items that met the elimination criteria, and all 25 items were retained (Table 2).

\section{Validity Analysis}

\section{Construct Validity Based on EFA}

Bartlett's test of sphericity for appropriate assumptions was significant $\left(\chi^{2}=9147.604, p<0.001\right)$, and the KMO value was 0.839 , which is well above the recommended 0.50 , indicating that the value is acceptable.

Five factors were extracted based on eigenvalues $\geq 1$, and the scree plot yielded a five-factor solution as well (Figure 1), with the five factors accounting for $80.38 \%$ of the variance. The results showed that the factor loading of each item was above 0.40 and without cross-loading (Table 2).

Based on the factor loading results and the item content, factor 1 reflected the need for physical comfort, proper nutrition, and the ability to carry out daily functions and was named as "physical needs". Factor 2 concentrated on patients' requirements for coping with negative emotions resulting from adverse reactions and interpersonal disturbances and was retained as "psycho-emotional needs". Factor 3 reflected patients' desire to obtain

Table I Demographic Characteristics of the Participants ( $\left.N=518, N_{1}=259, N_{2}=259\right)$

\begin{tabular}{|c|c|c|c|c|c|}
\hline Characteristics & Total $(\mathrm{N}=5 \mid 8)$ & EFA $\left(N_{1}=259\right)$ & CFA $\left(N_{2}=259\right)$ & $z / x^{2}$ & $P$ \\
\hline Gender & & & & 0.629 & 0.481 \\
\hline Male & 279 & 135 & 144 & & \\
\hline Female & 239 & 124 & 115 & & \\
\hline Age [mean (SD)] & $32.03(6.89)$ & $32.43(6.75)$ & $31.69(7.03)$ & 1.498 & 0.221 \\
\hline Ethnicity & & & & 1.734 & 0.188 \\
\hline Han ethnicity & 478 & 235 & 243 & & \\
\hline Ethnic minority & 40 & 24 & 16 & & \\
\hline Education & & & & 8.322 & 0.080 \\
\hline Primary School or below & 106 & 46 & 60 & & \\
\hline Junior High School & 188 & 91 & 97 & & \\
\hline Senior High School & 126 & 61 & 65 & & \\
\hline Junior College & 59 & 38 & 21 & & \\
\hline Bachelor's degree or above & 39 & 23 & 16 & & \\
\hline Marriage & & & & 1.362 & 0.506 \\
\hline Unmarried & 149 & 74 & 75 & & \\
\hline Married & 298 & 145 & 153 & & \\
\hline Others (widowed, divorced) & 71 & 40 & 31 & & \\
\hline Treatment period & & & & 1.887 & 0.389 \\
\hline$<2$ months & 264 & 125 & 139 & & \\
\hline $2-6$ months & 173 & 89 & 84 & & \\
\hline$>6$ months & 81 & 45 & 36 & & \\
\hline Treatment site & & & & 2.570 & 0.109 \\
\hline Hospital & 353 & 168 & 185 & & \\
\hline Home & 165 & 91 & 74 & & \\
\hline Family monthly income & & & & 0.804 & 0.848 \\
\hline$\leq 1999$ yuan & 162 & 77 & 85 & & \\
\hline 2000-4999 yuan & 235 & 118 & 117 & & \\
\hline$\geq 5000$ yuan & 121 & 64 & 57 & & \\
\hline
\end{tabular}

Abbreviations: SD, standard deviation; EFA, exploratory factor analysis, CFA, confirmatory factor analysis. 
Table 2 Item Analysis and Factor Loadings for the SCN-TB

\begin{tabular}{|c|c|c|c|c|c|c|}
\hline No. & Item & $\begin{array}{l}\text { Mean } \\
\text { (SD) }\end{array}$ & C.R. & $\begin{array}{l}\text { Item-Total } \\
\text { Correlation }\end{array}$ & $\begin{array}{l}\text { Factor } \\
\text { Loading }\end{array}$ & $h^{2}$ \\
\hline \multicolumn{7}{|c|}{ Factor I: Physical needs (Eigenvalue $=10.12, \%$ of variance $=40.49 \%$ ) } \\
\hline ql & Help me have a healthy diet and improved nutrition during illness. & $3.09(1.16)$ & $19.24 *$ & $0.66 *$ & 0.920 & 0.948 \\
\hline q2 & Teach me to how to perform appropriate daily exercises. & $3.07(1.18)$ & $16.42^{*}$ & $0.64 *$ & 0.919 & 0.612 \\
\hline q3 & $\begin{array}{l}\text { Help me to prevent or manage side effects (eg, joint pain, decreased } \\
\text { hearing, and impaired vision). }\end{array}$ & $3.19(1.09)$ & $14.98^{*}$ & $0.58^{*}$ & 0.916 & 0.968 \\
\hline q4 & Teach me to relieve physical discomfort (eg, fever, cough, night sweats). & $3.30(1.09)$ & $14.11 *$ & $0.60^{*}$ & 0.915 & 0.954 \\
\hline q5 & Remind and instruct me to attend physical examinations on time. & $3.21(1.26)$ & $20.65^{*}$ & $0.70^{*}$ & 0.552 & 0.956 \\
\hline \multicolumn{7}{|c|}{ Factor 2: Psycho-emotional needs (Eigenvalue=3.44, \% of variance=|3.78\%) } \\
\hline q6 & Help me to protect my privacy during treatment. & $3.25(1.17)$ & $15.73^{*}$ & $0.65^{*}$ & 0.893 & 0.861 \\
\hline q7 & $\begin{array}{l}\text { Help me to cope with negative emotions (eg, anxiety, fear) and relieve } \\
\text { psychological stress. }\end{array}$ & $3.23(1.21)$ & $17.88^{*}$ & $0.70^{*}$ & 0.884 & 0.789 \\
\hline १8 & Help me to engage in healthcare to build confidence in rehabilitation. & $3.23(1.02)$ & $10.38^{*}$ & $0.48^{*}$ & 0.878 & 0.869 \\
\hline q9 & Help me to build a positive attitude towards future life. & $3.26(1.22)$ & $17.89 *$ & $0.70^{*}$ & 0.810 & 0.855 \\
\hline q10 & $\begin{array}{l}\text { Teach me to cope with family-related issues caused by illness (eg, getting } \\
\text { married and having children). }\end{array}$ & $3.32(1.17)$ & $16.60^{*}$ & $0.68^{*}$ & 0.782 & 0.744 \\
\hline \multicolumn{7}{|c|}{ Factor 3: Informational needs (Eigenvalue $=2.69, \%$ of variance $=10.78 \%$ ) } \\
\hline qll & $\begin{array}{l}\text { Help me to obtain information about TB (eg, symptoms, transmission } \\
\text { routes). }\end{array}$ & $3.52(1.19)$ & $10.70 *$ & $0.53 *$ & 0.906 & 0.804 \\
\hline$q 12$ & Help me to understand my condition and test results. & $3.40(1.24)$ & $12.88^{*}$ & $0.58^{*}$ & 0.895 & 0.901 \\
\hline $\mathrm{q} 13$ & $\begin{array}{l}\text { Help me to understand the name of the medication, ways of taking it and } \\
\text { precautions. }\end{array}$ & $3.40(1.24)$ & $11.17^{*}$ & $0.52 *$ & 0.876 & 0.426 \\
\hline q14 & $\begin{array}{l}\text { Help me to obtain information about the schedule of treatment after } \\
\text { discharge. }\end{array}$ & $3.39(1.27)$ & $11.38 *$ & $0.53 *$ & 0.817 & 0.923 \\
\hline q15 & $\begin{array}{l}\text { Help me to know more about the treatment protocol and prognosis of } \\
\text { the disease. }\end{array}$ & $3.37(1.22)$ & $11.95^{*}$ & $0.56^{*}$ & 0.576 & 0.939 \\
\hline \multicolumn{7}{|c|}{ Factor 4: Social needs (Eigenvalue $=2.09, \%$ of variance $=8.40 \%$ ) } \\
\hline $\mathrm{q16}$ & $\begin{array}{l}\text { Help me to communicate with peer patients who have had similar } \\
\text { experiences. }\end{array}$ & $3.21(1.23)$ & $16.67 *$ & $0.64 *$ & 0.946 & 0.916 \\
\hline $\mathrm{q} 17$ & Teach me to obtain understanding and support from family and friends. & $3.33(1.84)$ & $17.82^{*}$ & $0.67 *$ & 0.916 & 0.669 \\
\hline q18 & Help me to participate in support groups and activities. & $3.27(1.23)$ & $18.75^{*}$ & $0.70^{*}$ & 0.857 & 0.529 \\
\hline q19 & $\begin{array}{l}\text { Teach me to cope with challenges related to changes in social } \\
\text { interactions after diagnosis. }\end{array}$ & $3.23(1.28)$ & $20.14^{*}$ & $0.69 *$ & 0.801 & 0.776 \\
\hline q20 & $\begin{array}{l}\text { Teach me to take effective measures to protect others from being } \\
\text { infected. }\end{array}$ & $3.30(1.28)$ & $19.22 *$ & $0.67^{*}$ & 0.660 & 0.875 \\
\hline
\end{tabular}

(Continued) 
Table 2 (Continued).

\begin{tabular}{|c|c|c|c|c|c|c|}
\hline No. & Item & $\begin{array}{l}\text { Mean } \\
\text { (SD) }\end{array}$ & C.R. & $\begin{array}{l}\text { Item-Total } \\
\text { Correlation }\end{array}$ & $\begin{array}{l}\text { Factor } \\
\text { Loading }\end{array}$ & $h^{2}$ \\
\hline \multicolumn{7}{|c|}{ Factor 5: Practical needs (Eigenvalue $=1.73, \%$ of variance $=6.93 \%$ ) } \\
\hline q21 & $\begin{array}{l}\text { Help me to obtain information about TB policies related to treatment } \\
\text { fee decreases or waivers. }\end{array}$ & $3.84(1.10)$ & $7.57^{*}$ & $0.43^{*}$ & 0.910 & 0.711 \\
\hline q22 & Help me to know the expenses of treatment. & $3.78(1.14)$ & $7.90 *$ & $0.37^{*}$ & 0.864 & 0.895 \\
\hline q23 & $\begin{array}{l}\text { Teach me to obtain timely and professional follow-up services after } \\
\text { discharge. }\end{array}$ & $3.47(0.87)$ & $7.24 *$ & $0.44 *$ & 0.786 & 0.577 \\
\hline q24 & Help me to learn and develop a healthy lifestyle. & $3.77(1.20)$ & $10.55^{*}$ & $0.50 *$ & 0.717 & 0.727 \\
\hline q25 & $\begin{array}{l}\text { Help me to establish a stable, long-term connection with healthcare } \\
\text { providers. }\end{array}$ & $3.86(1.12)$ & $9.32 *$ & $0.48 *$ & 0.609 & 0.869 \\
\hline
\end{tabular}

Notes: $h^{2}$ represents item communalities, *Statistically significant at $P$-value $<0.0$ I.

Abbreviations: SD, standard deviation; C.R., critical ratio value.

information regarding the disease, prognosis and treatment to reduce their confusion and anxiety and was named "informational needs". Factor 4 reflected involvement in family relationships and community acceptance and was termed "social needs". Factor 5 concentrated on long-term follow-up service and financial support and was named "practical needs".

\section{Construct Validity Based on CFA}

CFA revealed an acceptable fit of the five-factor model, which was indicated by $\chi^{2} / d f=1.062$ (Bollen-Stine $\left.\chi^{2}=281.382, \quad d f=265, \quad p<0.001\right), \quad$ CFI $=0.997$, RMSEA $=0.016, \quad$ SRMR $=0.053, \quad \mathrm{NFI}=0.951, \quad$ and $\mathrm{GFI}=0.929$. The bootstrapped standardized item loadings are shown in Figure 2.

\section{Convergent and Discriminant Validity}

The standardized factor loadings of all items were statistically significant and greater than 0.40 . The AVE of the five factors ranged from 0.578 to 0.734 . The CR values of the five factors ranged from 0.872 to 0.932 . Additionally, the square root of the AVE was greater than the correlation coefficients among the five factors (Table 3). The SCN-TB discriminated between the needs of patient subgroups. Females $(p=0.038)$, those with a treatment period shorter than 2 months $(p=0.017)$, and those who were recruited from the hospital $(p=0.026)$ had significantly higher levels of needs than their respective counterparts. There were no statistically significant differences in SCN-TB score by patient ethnicity $(p=0.48)$, education $(p=0.394)$, marital status $(p=0.061)$, or family income $(p=0.496)$.

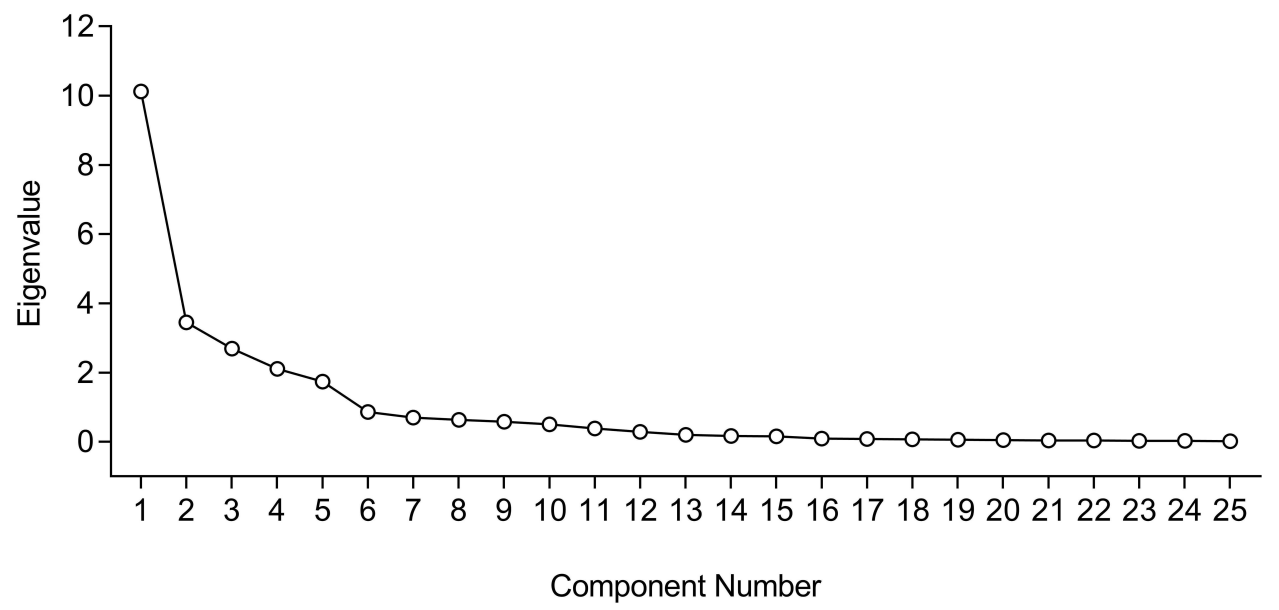

Figure I Scree plot of principal component factor analysis $\left(N_{1}=259\right)$. 


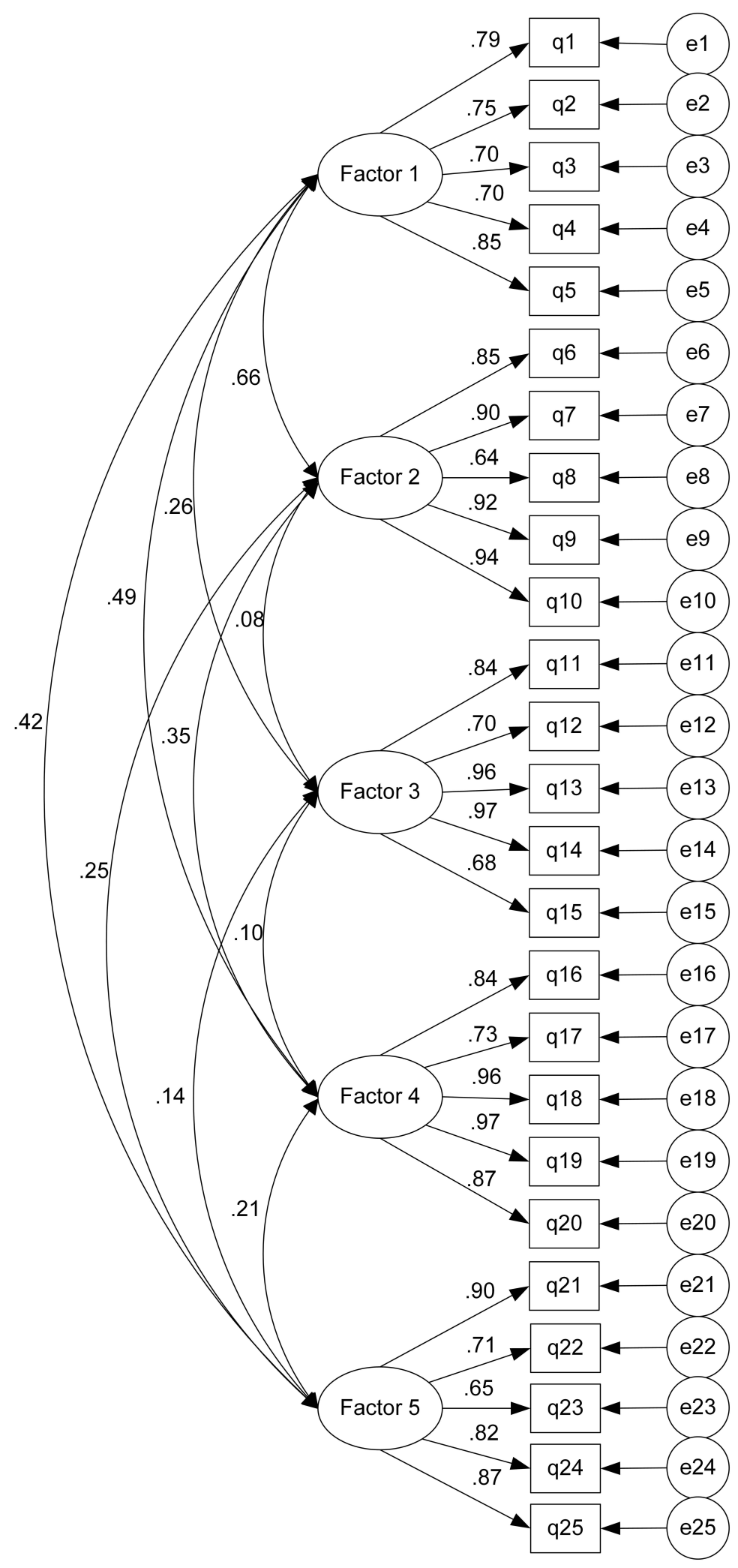

Figure 2 The bootstrapped standardized path diagram of the CFA model $\left(\mathrm{N}_{2}=259\right)$.

Notes: qI to q25 represent the items of the SCN-PTB, Factor I: Physical needs, Factor 2: Psycho-emotional needs, Factor 3: Informational needs, Factor 4: Social needs, Factor 5: Practical needs; e: measurement error. 
Table 3 Results of Convergent and Discriminant Validity Analysis

\begin{tabular}{|l|c|c|c|c|c|c|c|}
\hline Factor & CR & AVE & Factor I & Factor 2 & Factor 3 & Factor 4 & Factor 5 \\
\hline Factor I & 0.872 & 0.578 & $0.760^{*}$ & & & \\
Factor 2 & 0.932 & 0.734 & 0.657 & $0.857^{*}$ & & \\
Factor 3 & 0.921 & 0.704 & 0.260 & 0.076 & $0.839 *$ & \\
Factor 4 & 0.920 & 0.713 & 0.492 & 0.348 & 0.097 & $0.844^{*}$ & \\
Factor 5 & 0.895 & 0.633 & 0.421 & 0.252 & 0.138 & 0.206 & $0.796 *$ \\
\hline
\end{tabular}

Notes: Factor I: Physical needs, Factor 2: Psycho-emotional needs, Factor 3: Informational needs, Factor 4: Social needs, Factor 5: Practical needs; *Represents the square root of the AVE of five factors, the italic number represent the correlation coefficients between five factors.

Abbreviations: CR, construct reliability; AVE, average variance extracted.

\section{Reliability Analysis}

Cronbach's alpha for the 25 items was 0.884 and ranged from 0.794 to 0.906 for the individual domains. The split-half coefficient of the SCN-TB was 0.883 and ranged from 0.712 to 0.877 for the individual domains. The test-retest reliability coefficient of the total scale was 0.854 and ranged between 0.820 and 0.900 for the individual domains (Table 4).

\section{Discussion}

Accurately assessing TB patients' SCN is pivotal to achieving positive health outcomes within the clinical context. This study performed the first step in developing a more comprehensive scale to measure the SCN of TB patients, constructing the SCN-TB, which encompasses five domains and 25 items: physical, psycho-emotional, informational, social, and practical. The results of the initial psychometric assessment showed that the SCN-TB has a robust factor structure and adequate reliability coefficients.

Drawing on the SCNF helped us to identify five domains that reflect the needs of patients with TB. "Physical needs" is the first domain and had the highest impact score on the SCN$\mathrm{TB}$, indicating that an individual's physical needs deserve more attention. For patients with TB, the major physical problems influencing health are those related to disease symptoms and treatment-related side effects. ${ }^{10}$ Items related to nutritional and exercise guidance were also included in this domain, which emphasizes the importance of a healthy lifestyle in TB treatment. ${ }^{9}$

TB patients often experience considerable emotional and psychological distress, such as anxiety, stigma and fear, as a result of their condition. ${ }^{12}$ Their psychoemotional needs are related to help in developing individual coping and mental regulation strategies. Related to this, spiritual needs are related to finding meaning and purpose in life, ${ }^{24}$ which affects an individuals's mental states. $^{42}$ However, relevant needs have rarely been reported in the TB literature. Thus, an item titled "Help me to build a positive attitude towards future life" was embedded in the domain of psycho-emotional needs to ensure that spiritual-related needs were captured.

Improving patients' TB knowledge is an essential component of health education. ${ }^{43}$ According to previous studies, effective communication regarding risk factors, treatment regimens and plans, medication, therapeutic effects and prognosis is widely perceived by TB patients as the most important issue. 9,15 Therefore, these concerns were all included in the "informational needs" domain. Effectively communicating essential information may empower $\mathrm{TB}$ patients to engage in their healthcare and assist them in making informed decisions about treatment options.

In the realm of social activities, TB patients' needs are often created and satisfied through interpersonal interaction, communication, and community participation.

Table 4 Reliability of the SCN-TB

\begin{tabular}{|l|c|c|c|}
\hline Domain & Cronbach's $\alpha$ & Split-Half Reliability & Test-Retest Reliability \\
\hline Physical needs & 0.794 & 0.712 & $0.820^{*}$ \\
Psycho-emotional needs & 0.882 & 0.842 & $0.854^{*}$ \\
Informational needs & 0.856 & 0.877 & $0.84 I^{*}$ \\
Social needs & 0.906 & 0.835 & $0.900^{*}$ \\
Practical needs & 0.850 & 0.794 & $0.843^{*}$ \\
Total & 0.884 & 0.883 & $0.854^{*}$ \\
\hline
\end{tabular}

Note: *Correlation is significant at the 0.01 level (2-tailed). 
Previous studies confirmed that support and encouragement from peers and family members were highly valued by TB patients. ${ }^{13}$ The patients also expressed a desire for more participation on a societal level. This desire may stem from the experience of stigmatization, which is regarded as a major challenge among TB patients. ${ }^{44}$

The domain of practical needs encompasses distinctive items concerning follow-up service and financial support, which are not covered by existing tools. Recent evidence has demonstrated that the financial burden is a large barrier for TB patients, and they are eager to seek available resources to alleviate their economic burden. ${ }^{45}$ Effective follow-up services can not only help TB patients complete their regimen but also provide ongoing support for them during home-based treatment. ${ }^{14}$ For this reason, measuring patient perception of these concerns and what they can obtain from healthcare professionals could provide information to address specific weakness in TB care. Consequently, the SCN-TB could be considered a more comprehensive questionnaire for investigating such patient needs, which is consistent with the WHO recommendations regarding TB patient-centred care. ${ }^{17}$ After being reviewed twice by an expert panel, the CVI of each item ranged between 0.80 and 1.00 , and S-CVI was 0.93 , indicating that the SCN-TB has reasonable content validity and authenticity regarding what it was supposed to measure. $^{30}$

Construct validity was demonstrated by EFA and CFA. In the EFA, the five extracted factors accounted for $80.38 \%$ of the variability, indicating that the underlying factors were meaningful. ${ }^{36}$ CFA was performed to confirm the structure of the scale for the other sample. In this study, the conceptual structure of the scale was successfully identified with CFA according to the $\chi^{2} / d f$, CFI, RMSEA, SRMR, NFI, and GFI fit indices. In addition, the AVE and CR values indicate good discriminant and convergent validity according to the criteria of AVE $>0.50$ and CR $>0.70$, and the square root of the AVE is larger than the correlation coefficients between factors. ${ }^{40}$ Meanwhile, there were differences in SCN-TB total scores according to patient gender, treatment period, and place, which supports known group discriminant validity. In general, the results confirmed the construct validity of the SCN-TB.

Regarding the internal consistency and split-half reliability, the results at the domain and scale levels were greater than 0.70 and indicated a satisfactory degree of consistency between items and each subscale of the SCN-
TB. ${ }^{41}$ Test-retest reliability refers to the temporal stability of an instrument over time. The overall test-retest reliability coefficient was 0.854 , and the correlation coefficient of each domain was between 0.841 and 0.900 , indicating that the SCN-TB has acceptable stability over time. Therefore, this scale is reliable.

\section{Implications for Practice}

The SCN-TB could be a useful tool in both clinical practice and research. Health professionals can use it to investigate TB patient needs and deliver tailored services to them. For researchers, measuring needs can help evaluate the effectiveness of existing health services or programs and identify areas for improvement. Furthermore, as needs may vary according to the characteristics of patients (eg, gender, treatment period and drug resistance etc), the SCN-TB makes it possible for clinicians to identify changing needs. Longitudinal studies that will enrich understanding of TB patient needs are warranted.

\section{Limitations}

This new instrument demonstrated excellent psychometric properties for assessing SCN in Chinese TB patients. However, it still has several limitations. First, participants in this study were only recruited from Shaanxi Province, limiting the generalizability of the SCN-TB to other settings. Furthermore, this study was conducted in the context of China, and it is not clear whether measurements of SCN are invariant across different cultures. Therefore, additional large-scale studies in other countries are necessary to confirm whether this scale is globally applicable. Finally, as there is no reliable scale currently available, we adopted various methods of psychometric evaluation, but criterion-related validity cannot be analysed, suggesting the need for further validation.

\section{Conclusion}

The SCN-TB was developed following the steps of scale development based on the theoretical framework. This scale includes 25 items divided into five dimensions reflecting physical, psycho-emotional, social, informational, and practical needs. The present study showed that the SCN-TB had good psychometric properties. It may be a useful tool for assessing TB patients' needs and can be applied in both clinical practice and research. 


\section{Data Sharing Statement}

The data underlying this article will be shared on a reasonable request to the corresponding author.

\section{Ethical Considerations}

This study was conducted in accordance with the Declaration of Helsinki and was approved by the Ethics Committee of Xi'an Jiaotong University (No. 2020-1244), and written informed consent was obtained from all participants before filling the survey. The investigation process adhered to the principles of confidentiality, with the questionnaires completed anonymously, and the research data were used only in this research.

\section{Acknowledgments}

We are grateful to the experts who reviewed this scale, the patients who participated in the study, and the doctors and nurses who helped us in recruiting patients.

\section{Author Contributions}

All authors made substantial contributions to conception and design, acquisition of data, or analysis and interpretation of data; took part in drafting the article or revising it critically for important intellectual content; agreed to submit to the current journal and gave final approval of the version to be published, and agreed to be accountable for all aspects of the work.

\section{Funding}

This work was supported by the China Medical Board (CMB) program [11-085].

\section{Disclosure}

The authors declared that no potential conflicts of interest with respect to the research, authorship, and/or publication of this article.

\section{References}

1. World Health Organization. Global tuberculosis report 2020. Licence: CC BY-NC-SA 3.0 IGO. Geneva, Switzerland: World Health Organization; 2020. Available from: https://apps.who.int/iris/handle/ 10665/336069. Accessed September 28, 2021.

2. Wurie FB, Cooper V, Horne R, Hayward AC. Determinants of non-adherence to treatment for tuberculosis in high-income and middle income settings: a systematic review protocol. BMJ Open. 2018;8(1): e019287. doi:10.1136/bmjopen-2017-019287

3. Jing R, Quanlei L, Tianhua Z, et al. Perceptions of engagement in health care among patients with tuberculosis: a qualitative study. Patient Prefer Adherence. 2019;13:107-117. doi:10.2147/PPA. S191800
4. Min J, Chung C, Jung SS, et al. Understanding illness perception in tuberculosis patients: one step towards patient-centered care. PLoS One. 2019;14(6):e0218106. doi:10.1371/journal.pone.0218106

5. Oshi D, Chukwu J, Nwafor C, et al. Support and unmet needs of patients undergoing multidrug-resistant tuberculosis (MDR-TB) treatment in southern Nigeria. Int $J$ Health Plann Manage. 2020;35 (4):832-842. doi:10.1002/hpm.2929

6. Wu C-Y. Needs assessments enhance patient-centered care quality. J Nurs Res. 2019;27(6):e49. doi:10.1097/jnr.0000000000000365

7. Ream E, Quennell A, Fincham L, et al. Supportive care needs of men living with prostate cancer in England: a survey. $\mathrm{Br} J$ Cancer. 2008;98(12):1903-1909. doi:10.1038/sj.bjc.6604406

8. Cramp F, Bennett MI. Development of a generic working definition of 'supportive care'. BMJ Support Palliat Care. 2013;3:53-60. doi:10.1136/bmjspcare-2012-000222

9. Alipanah N, Jarlsberg L, Miller C, et al. Adherence interventions and outcomes of tuberculosis treatment: a systematic review and meta-analysis of trials and observational studies. PLoS Med. 2018;15:e1002595. doi:10.1371/journal.pmed.1002595

10. Ravimohan S, Kornfeld H, Weissman D, Bisson GP. Tuberculosis and lung damage: from epidemiology to pathophysiology. Eur Respir Rev. 2018;27:147. doi:10.1183/16000617.0077-2017

11. Gyimah FT, Dako-Gyeke P. Perspectives on TB patients' care and support: a qualitative study conducted in Accra Metropolis, Ghana. Glob Health. 2019;15(1):19. doi:10.1186/s12992-019-0459-9

12. Shiratani KN. Psychological changes and associated factors among patients with tuberculosis who received directly observed treatment short-course in metropolitan areas of Japan: quantitative and qualitative perspectives. BMC Public Health. 2019;19(1):1642. doi:10.1186/ s12889-019-8001-9

13. Li X, Wang B, Tan D, et al. Effectiveness of comprehensive social support interventions among elderly patients with tuberculosis in communities in China: a community-based trial. $J$ Epidemiol Community Health. 2018;72(5):369-375. doi:10.1136/jech-2017209458

14. Aibana O, Dauria E, Kiriazova T, et al. Patients' perspectives of tuberculosis treatment challenges and barriers to treatment adherence in Ukraine: a qualitative study. BMJ Open. 2020;10(1):e032027. doi:10.1136/bmjopen-2019-032027

15. Pai M, Yadav P, Anupindi R. Tuberculosis control needs a complete and patient-centric solution. Lancet Global Health. 2014;2(4):e189e190. doi:10.1016/S2214-109X(14)70198-6

16. Odone A, Roberts B, Dara M, et al. People- and patient-centred care for tuberculosis: models of care for tuberculosis. Int J Tuberc Lung Dis. 2018;22(2):133-138. doi:10.5588/ijtld.17.0608

17. World Health Organization. Guidelines for treatment of drug-susceptible tuberculosis and patient care, 2017 update. License: CC-BY-NC-SA 3.0 IGO. Geneva: World Health Organization; 2017. Available from: https://apps.who.int/iris/handle/ 10665/255052. Accessed September 28, 2021.

18. Suryani S, Widianti E, Hernawati T, Sriati A. Psychosocial need analysis of patients with tuberculosis. Makara $J$ Health Res. 2014;18(3):127-134. doi:10.7454/msk.v18i3.4471

19. Abdulelah J, Sulaiman S, Hassali MA, et al. Development and psychometric properties of a tuberculosis specific multidimensional health-related quality of life measure for patients with tuberculosis. Value Health Reg Issues. 2015;6:53-59. doi:10.1016/j. vhri.2015.03.006

20. Pasipanodya JG, Miller TL, Vecino M, et al. George respiratory questionnaire to ascertain health quality in persons with treated pulmonary tuberculosis. Chest. 2007;132(5):1591-1598. doi:10.1378/chest.07-0755

21. Valery PC, Bernardes CM, Stuart KA, et al. Development and evaluation of the Supportive Needs Assessment Tool for Cirrhosis (SNAC). Patient Prefer Adherence. 2020;14:599-611. doi:10.2147/ PPA.S236818 
22. Valery PC, Powell E, Moses N, et al. Systematic review: unmet supportive care needs in people diagnosed with chronic liver disease. BMJ Open. 2015;5(4):e007451. doi:10.1136/bmjopen-2014007451

23. Busolo DS, Woodgate RL. Using a supportive care framework to understand and improve palliative care among cancer patients in Africa. Palliat Support Care. 2016;14(3):284-301. doi:10.1017/ S1478951515000796

24. Fitch MI. Supportive care framework. Can Oncol Nurs J. 2008;18 (1):6-24. doi:10.5737/1181912x181614

25. De Socio GV, Penn AW, Azman H, et al. Supportive interventions to improve retention on ART in people with HIV in low- and middle-income countries: a systematic review. PLoS One. 2018;13 (12). doi:10.1371/journal.pone.0208814

26. MacIsaac L, Harrison MB, Godfrey C. Supportive care needs of caregivers of individuals following stroke: a synopsis of research. Can J Neurosci Nurs. 2010;32(1):39-46.

27. Staff A, Garvin P, Wirehn AB, Yngman-Uhlin P. Patients requests and needs for culturally and individually adapted supportive care in type 2 diabetes patients: a comparative study between Nordic and non-Nordic patients in a social economical vulnerable area of Linkoping, Sweden. Prim Care Diabetes. 2017;11(6):522-528. doi:10.1016/j.pcd.2017.06.006

28. McElduff P, Boyes A, Zucca A, Girgis A. Supportive Care Needs Survey: A Guide to Administration, Scoring and Analysis. Newcastle: Centre for Health Research \& Psycho-Oncology; 2004.

29. Keeney S, Hasson F, McKenna HP. A critical review of the Delphi technique as a research methodology for nursing. Int J Nurs Stud. 2001;38(2):195-200. doi:10.1016/S0020-7489(00)00044-4

30. Polit DF, Beck CT, Owen SV. Is the CVI an acceptable indicator of content validity? Appraisal and recommendations. Res Nurs Health. 2007;30:459-467. doi:10.1002/nur.20199

31. Boateng GO, Neilands TB, Frongillo EA, et al. Best practices for developing and validating scales for health, social, and behavioral research: a primer. Front Public Health. 2018;6:149. doi:10.3389/ fpubh.2018.00149

32. Kyriazos TA. Applied psychometrics: sample size and sample power considerations in factor analysis (EFA, CFA) and SEM in general. Psychology. 2018;09(08):2207-2230. doi:10.4236/psych.2018.98126

33. Lee E-H, Lee YW, Lee K-W, Nam M, Kim SH. A new comprehensive diabetes health literacy scale: development and psychometric evaluation. Int $J$ Nurs Stud. 2018;88:1-8. doi:10.1016/j. ijnurstu.2018.08.002
34. Cao Y, Chen W, Zhang S, et al. Development and preliminary evaluation of psychometric properties of a Tuberculosis Self-Efficacy Scale (TBSES). Patient Prefer Adherence. 2019;13:1817-1827. doi:10.2147/PPA.S208336

35. Rattray J, Jones MC. Essential elements of questionnaire design and development. J Clin Nurs. 2007;16(2):234-243. doi:10.1111/j.13652702.2006.01573.x

36. Yong AG, Pearce S. A beginner's guide to factor analysis: focusing on exploratory factor analysis. Tutor Quant Methods Psychol. 2013;9 (2):79-94. doi:10.20982/tqmp.09.2.p079

37. Gorsuch RL. Exploratory factor analysis: its role in item analysis. $J$ Pers Assess. 1997;68(3):532-560. doi:10.1207/s1532775 2jpa6803 5

38. Bollen KA, Stine RA. Bootstrapping goodness-of-fit measures in structural equation models. Sociol Methods Res. 2016;21 (2):205-229. doi:10.1177/0049124192021002004

39. Jackson DL, Gillaspy JA, Purc-Stephenson R. Reporting practices in confirmatory factor analysis: an overview and some recommendations. Psychol Methods. 2009;14(1):6-23. doi:10.1037/ a0014694

40. Henseler J, Ringle CM, Sarstedt M. A new criterion for assessing discriminant validity in variance-based structural equation modeling. J Acad Mark Sci. 2014;43:115-135. doi:10.1007/s11747-014-0403-8

41. Souza AC, Alexandre NMC, Guirardello EB, Souza ACD, Alexandre NMC, Guirardello EDB. Psychometric properties in instruments evaluation of reliability and validity. Epidemiol Serv Saude. 2017;26(3):649-659. doi:10.5123/S1679-4974201700 0300022

42. Büssing A, Zhai XF, Peng WB, Ling CQ. Psychosocial and spiritual needs of patients with chronic diseases: validation of the Chinese version of the Spiritual Needs Questionnaire. J Integr Med. 2013;11 (2):106-115. doi:10.3736/jintegrmed2013020

43. Kigozi NG, Heunis JC, Engelbrecht MC, et al. Tuberculosis knowledge, attitudes and practices of patients at primary health care facilities in a South African metropolitan: research towards improved health education. BMC Public Health. 2017;17(1):795. doi:10.1186/ s12889-017-4825-3

44. Lee LY, Tung HH, Chen SC, Fu CH. Perceived stigma and depression in initially diagnosed pulmonary tuberculosis patients. J Clin Nurs. 2017;26:4813-4821. doi:10.1111/jocn.13837

45. Zhou C, Long Q, Chen J, et al. Factors that determine catastrophic expenditure for tuberculosis care: a patient survey in China. Infect Dis Poverty. 2016;5:6. doi:10.1186/s40249-016-0100-6
Patient Preference and Adherence

\section{Publish your work in this journal}

Patient Preference and Adherence is an international, peer-reviewed, open access journal that focusing on the growing importance of patient preference and adherence throughout the therapeutic continuum. Patient satisfaction, acceptability, quality of life, compliance, persistence and their role in developing new therapeutic modalities and compounds to optimize clinical outcomes for existing disease states are major areas of interest for the journal. This journal has been accepted for indexing on PubMed Central. The manuscript management system is completely online and includes a very quick and fair peer-review system, which is all easy to use. Visit http:// www.dovepress.com/testimonials.php to read real quotes from published authors. 